\title{
Padrão de resistência de genótipos de aveia à ferrugem-da-folha na definição de hibridações
}

\author{
Eduardo Alano Vieira ${ }^{(1)}$, Fernando Irajá Félix de Carvalho(2), Márcia Soares Chaves ${ }^{(3)}$, Antonio Costa de Oliveira(2), \\ Ivandro Bertan ${ }^{(2)}$, Andreza Figueirola Martins ${ }^{(2)}$, Irineu Hartwig ${ }^{(2)}$, Giovani Benin ${ }^{(4)}$, Igor Pirez Valério(2) \\ e Daniel Andrei Robe Fonseca(2)
}

\begin{abstract}
(1)Embrapa Cerrados, Br 020, Km 18, Caixa Postal 08223, CEP 73310-970 Planaltina, DF. E-mail: vieiraea.cpac.embrapa.br (2)Universidade Federal de Pelotas, Fac. de Agronomia Eliseu Maciel, Dep. de Fitotecnia, Campus Universitário, s/non, CEP 96010-900 Pelotas, RS. E-mail: carvalho@ufpel.tche.br, acostol@terra.com.br, ivandrobertan@yahoo.com.br, dezafm@terra.com.br, iriwig@ufpel.tche.br, igorvalerio@hotmail.com, danielfonseca30@yahoo.com.br (3)Embrapa Trigo, Rod. BR 285, Km 174, Caixa Postal 451, CEP 99001-970 Passo Fundo, RS. E-mail: mchaves@cnpt.embrapa.br (4)Universidade Tecnológica Federal do Paraná, Curso de Agronomia, Rod. PR 469, Km 01, CEP 85501-970 Pato Branco, PR. E-mail: benin@pb.cefetpr.br
\end{abstract}

Resumo - Os objetivos deste trabalho foram: determinar o padrão de resistência/suscetibilidade de 20 genótipos de aveia a 40 isolados de Puccinia coronata f. sp. avenae, coletados em três municípios do Rio Grande do Sul; o padrão de virulência/avirulência desses isolados contra os genótipos de aveia; e indicar genitores para a geração de populações com elevada resistência à ferrugem-da-folha. Os padrões de resistência de Puccinia coronata f. sp. avenae e o de virulência/avirulência dos isolados foram determinados pela avaliação da reação desencadeada pela aspersão dos isolados deste fungo em plântulas de genótipos de aveia. A seleção de genitores foi baseada no índice de complementação de cultivares, proposto neste trabalho. Os genótipos que expressaram resistência ao maior número de isolados foram FAPA6, URS20, UPFA20, CFT1 e FAPA5, ao passo que os genótipos UFRGS15, UPF15, UPF18, UPF19 e UPF16 evidenciaram suscetibilidade ao maior número de isolados. Os cruzamentos mais indicados entre os genótipos estudados são: FAPA6 x Albasul, URS22 x FAPA6, CFT1 x URPEL15 e CFT1 x UFRGS19.

Termos para indexação: Avena sativa, Puccinia coronata, resistência genética, melhoramento de plantas.

\section{Resistance pattern of white oat genotypes to crown rust in the definition of crosses}

\begin{abstract}
The objectives of this work were: to determine the resistance/susceptibility pattern of 20 elite oat genotypes to 40 isolates of Puccinia coronata f. sp. avenae; to determine the pattern of virulence/avirulence of isolates collected in three counties of Rio Grande do Sul to the oat genotypes studied; and to indicate potential parents for the generation of populations with high crown rust resistance. The resistance pattern of oat genotypes and the virulence/avirulence of the fungi were determined by the analysis of the reaction incited by the inoculation of Puccinia coronata f. sp. avenae isolates into seedlings of oat genotypes. The selection of genitors was based on the cultivar complementation index proposed in this work. Genotypes expressing resistance to the larger number of isolates were FAPA6, URS20, UPFA20, CFT1 and FAPA5, while UFRGS15, UPF15, UPF18, UPF19 and UPF16 were susceptible to a higher number of isolates. The following crosses are indicated: FAPA6 x Albasul, URS22 x FAPA6, CFT1 x URPEL15 and CFT1 x UFRGS19.
\end{abstract}

Index terms: Avena sativa, Puccinia coronata, genetic resistance, plant breeding.

\section{Introdução}

A ferrugem-da-folha da aveia, causada pelo fungo Puccinia coronata f. sp. avenae, é a mais disseminada e severa doença que ameaça esta cultura (Simons \& Murphy, 1961). O fungo pertence à família Pucciniaceae, ordem Uredinales, classe Basidiomycotina, e foi relatado pela primeira vez nos EUA, por C.H. Peck, em 1872, e atualmente está distribuído em várias partes do mundo (Simons, 1985).
No Brasil, a ferrugem-da-folha é, também, a principal doença da aveia - a ocorrência do patógeno é verificada em praticamente todos os anos, podendo causar severas epidemias em genótipos suscetíveis, quando as condições de ambiente são favoráveis (temperatura amena e elevada umidade relativa do ar). A doença provoca redução significativa no rendimento e na qualidade de grãos, em cultivares suscetíveis (Martinelli et al., 1994; Caierão et al., 2001; Doehlert et al., 2001; Holland \& Munkvold, 2001; Lorencetti et al., 2004; Benin et al., 2005). 
As formas mais empregadas para o controle da ferrugem-da-folha da aveia são a utilização de fungicidas e de variedades resistentes - esta última é considerada a opção mais barata e ambientalmente favorável de controle, uma vez que o uso de produtos químicos eleva os custos de produção e pode ocasionar sérios prejuízos ao ambiente e às comunidades rurais. Entretanto, os melhoristas de aveia vêm enfrentando grandes dificuldades, pois os genótipos resistentes à ferrugemda-folha não têm mantido a resistência por muito tempo. A falta de durabilidade da resistência é atribuída à grande variabilidade de virulência que o patógeno apresenta, bem como à sua habilidade de desenvolver novos biótipos capazes de infectar os genótipos que apresentam resistência do tipo monogênica (Chong \& Seaman, 1994b).

Uma das etapas mais importantes e que define o sucesso de um programa de melhoramento genético é a escolha de genitores. A obtenção de êxito, nessa etapa, depende do conhecimento da variabilidade genética e da capacidade de complementação do germoplasma disponível (Falconer \& Mackay, 1996). No melhoramento para resistência a moléstias, como demonstrado por Flor (1956), a resistência ou suscetibilidade do hospedeiro ao fungo causador de ferrugem e a avirulência ou virulência do patógeno, em relação ao hospedeiro, são a expressão da interação dos complexos gênicos do hospedeiro e do patógeno, influenciados pelo ambiente, que atua sobre o hospedeiro e o patógeno, individualmente, e sobre a interação de ambos. No que diz respeito à resistência à moléstia, o cenário é mais complexo do que para os demais caracteres de interesse agronômico, uma vez que é necessário conhecimento sobre a variabilidade do hospedeiro (resistência/ suscetibilidade) e do patógeno (virulência/avirulência) para que o melhorista consiga definir, de forma mais precisa, as estratégias de melhoramento a serem empregadas.

Os objetivos deste trabalho foram: determinar o padrão de resistência/suscetibilidade de 20 genótipos de aveia a 40 isolados de Puccinia coronata f. sp. avenae, coletados em três municípios do Estado do Rio Grande do Sul; determinar o padrão de virulência/avirulência desses isolados contra os genótipos de aveia; e indicar possíveis genitores para a geração de populações segregantes com elevada resistência à ferrugem-dafolha da aveia.

\section{Material e Métodos}

Quarenta isolados do fungo Puccinia coronata f. sp. avenae foram utilizados no estudo, com seus padrões de virulência/avirulência a 25 genes $P_{c}(40,45,46,50$, $38,39,48,68,51,52,58,59,54,56,62,64,14,35,36,53$, $55,57,60,61$ e 63) determinados por Vieira (2005). Os isolados foram coletados em setembro de 2003, sobre folhas de aveia com sinais da ferrugem característica desses fungos, em cultivares do Ensaio Brasileiro de Cultivares Recomendadas de Aveia (EBCRA), em três municípios do Estado do Rio Grande do Sul, sendo $15 \mathrm{em}$ Passo Fundo, a $28^{\circ} 15$ 'S, 52 $24^{\circ} \mathrm{O}$ e altitude de $687 \mathrm{~m}$; 12 em Capão do Leão, a $31^{\circ} 52^{\prime} \mathrm{S}, 52^{\circ} 21^{\prime} \mathrm{O}$ e altitude de

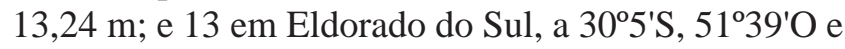
altitude de $46 \mathrm{~m}$. A identificação do local, data e cultivar sobre a qual os isolados foram obtidos, bem como os genes de virulência presentes em cada isolado, com base em 25 genes $P c$ utilizados, estão descritos na Tabela 1.

Esporos dos 40 isolados foram suspensos em água, na concentração de $10^{5} \mathrm{~mL}^{-1}$, e aspergidos sobre plântulas com a primeira folha completamente expandida (sete dias depois da semeadura), dos 20 genótipos de aveia estudados (Tabela 2). Antes da aspersão com os esporos dos isolados, as plântulas foram borrifadas com água, contendo Tween 20 na concentração de $10 \mu \mathrm{L} 100 \mathrm{~mL}^{-1}$ e, em seguida, foram mantidas em câmara úmida, no escuro, por 18 horas, à temperatura de $20-24^{\circ} \mathrm{C}$ e umidade de $100 \%$, para garantir a germinação dos esporos e a penetração dos fungos na folha. Depois deste período, as plântulas foram transferidas para uma casa de vegetação, com temperatura $\left(20-24^{\circ} \mathrm{C}\right)$ e umidade $(60-80 \%)$ controladas.

Quinze dias depois da aspersão dos fungos nos genótipos de aveia, as plantas foram avaliadas e, para a distinção entre alto e baixo tipo de infecção, foi utilizado o critério descrito por Chong et al. (2000). Foi empregada escala quantitativa, com notas de 0 a 4 , em que (0) é a ausência de urédia ou outros sinais macroscópicos de infecção; (;) é a presença de reação marcante de hipersensibilidade sem esporulação; (1) é a pequena urédia rodeada por clorose ou necrose; (2) é a urédia, com tamanho de pequeno a médio, rodeada por clorose; (3) é a urédia de tamanho médio, em área clorótica; e (4) é a grande urédia, sem clorose ou necrose. As notas (0), (;), (1) e (2) foram consideradas como indicativas de resistência do hospedeiro (baixo tipo de infecção), e as notas (3) e (4) foram consideradas como indicativas 
de suscetibilidade do hospedeiro (alto tipo de infecção). Cada isolado apresentou padrão próprio de alto e baixo tipo de infecção (virulência/avirulência), para os 20 genótipos utilizados, e cada genótipo também apresentou padrão próprio de resistência/suscetibilidade aos 40 isolados.
Posteriormente, os dados dos padrões de virulência/ avirulência dos isolados, para cada um dos genótipos estudados, foram transformados para escala binária, em que 1 é o alto tipo de infecção/virulência, e 0 é o baixo tipo de infecção/avirulência. A similaridade para virulência, entre cada um dos pares de isolados estudados,

Tabela 1. Relação dos 40 isolados de Puccinia coronata f. sp. avenae, com a indicação dos códigos utilizados, locais de coleta, cultivares nas quais foram coletados, genes $P c$ aos quais são virulentos, e número de genes de virulência evidenciados a 25 Pc empregados no estudo.

\begin{tabular}{|c|c|c|c|c|}
\hline Código & Origem do isolado & Cultivar & Genes de virulência presentes & $\begin{array}{c}\text { Número de genes } \\
\text { de virulência }\end{array}$ \\
\hline EL1 & Eldorado do Sul & UPF16 & $40,45,46,48,51,59,56,64,36,53,55,35,57,60$ е 61 & 15 \\
\hline EL2 & Eldorado do Sul & UPF16 & $40,45,46,48,51,52,58,59,56,64,36,53,55,14,35,57,60$ e 61 & 18 \\
\hline EL3 & Eldorado do Sul & UPF16 & $40,45,46,51,58,59,56,64,36,53,55,14,35,57,60$ e 61 & 16 \\
\hline EL4 & Eldorado do Sul & UFRGS15 & $40,45,46,39,51,52,58,59,54,56,64,36,55,14,57,60$ e 61 & 17 \\
\hline EL5 & Eldorado do Sul & UFRGS15 & $40,45,46,39,48,51,52,58,59,54,56,64,36,55,14,35,57,60$ e 61 & 19 \\
\hline EL6 & Eldorado do Sul & URS20 & $40,45,39,51,52,58,59,54,56,62,64,36,53,55,14,35,57,60$ e 61 & 19 \\
\hline EL7 & Eldorado do Sul & URS20 & $40,45,46,51,58,59,54,56,64,36,53,14,35,57,60$ e 61 & 16 \\
\hline EL8 & Eldorado do Sul & URS21 & $40,45,46,51,58,59,56,64,36,53,14,35,57,60$ e 61 & 15 \\
\hline EL9 & Eldorado do Sul & URS2 1 & $40,45,46,48,51,52,58,59,56,64,36,53,14,35,57,60$ e 61 & 17 \\
\hline EL10 & Eldorado do Sul & URS21 & $40,45,46,48,51,52,58,59,56,64,36,53,14,35,57,60$ e 61 & 17 \\
\hline EL11 & Eldorado do Sul & URS22 & $40,45,46,39,48,51,52,58,59,54,56,64,36,53,55,14,35,57,60$ e 61 & 20 \\
\hline EL12 & Eldorado do Sul & URS22 & $40,45,46,39,48,51,52,58,54,56,64,36,55,14,35,57,60$ e 61 & 18 \\
\hline EL13 & Eldorado do Sul & URS22 & $40,45,46,39,48,51,52,58,59,54,56,64,36,55,14,35,57,60$ e 61 & 19 \\
\hline EL14 & Eldorado do Sul & Albasul & $40,45,46,38,39,48,51,52,58,59,54,64,36,53,55,63,14,35,57,60$ e 61 & 21 \\
\hline EL15 & Eldorado do Sul & Albasul & $40,45,46,39,48,51,52,59,54,56,64,36,53,55,14,35,57,60$ e 61 & 19 \\
\hline CL1 & Capão do Leão & UPF16 & $40,45,46,48,51,58,59,54,56,64,53,35,57,60$ e 61 & 15 \\
\hline CL2 & Capão do Leão & UPF16 & $40,45,46,39,51,58,54,56,36,55,14,35,57$ e 61 & 14 \\
\hline CL3 & Capão do Leão & UPFA20 & $40,45,46,51,58,54,56,64,36,55,14,35,57,60$ e 61 & 15 \\
\hline CL4 & Capão do Leão & UPFA20 & $40,45,46,38,39,51,58,54,64,36,55,63,14,57,60$ e 61 & 16 \\
\hline CL5 & Capão do Leão & UPFA20 & $40,45,46,50,38,39,51,58,59,54,56,62,64,36,55,63,14,35,57,60$ e 61 & 21 \\
\hline CL6 & Capão do Leão & UFRGS15 & $40,45,46,50,39,51,58,54,64,36,53,55,14,35,57,60$ e 61 & 17 \\
\hline CL7 & Capão do Leão & URS20 & $40,45,46,38,39,51,59,54,64,36,55,63,14,35,57,60$ e 61 & 17 \\
\hline CL8 & Capão do Leão & URS20 & $40,45,46,38,51,59,54,56,64,55,63,14,35,57,60$ e 61 & 16 \\
\hline CL9 & Capão do Leão & URS20 & $40,45,46,38,39,48,51,52,58,54,56,64,36,55,63,14,35,57,60$ e 61 & 20 \\
\hline CL10 & Capão do Leão & URS22 & $40,45,46,39,48,51,52,59,54,56,64,36,55,14,35,57,60$ e 61 & 18 \\
\hline CL11 & Capão do Leão & Albasul & $40,45,46,48,51,52,58,59,56,64,36,53,14,35,57,60$ e 61 & 17 \\
\hline CL12 & Capão do Leão & Albasul & $40,45,46,48,51,52,58,59,56,36,53$ e 61 & 12 \\
\hline PF1 & Passo Fundo & UPF16 & $40,45,46,51,58,59,56,64,36,53,14,35,57,60$ e 61 & 15 \\
\hline PF2 & Passo Fundo & UPFA20 & $40,45,46,38,54,64,53,55,63,35,57$ e 60 & 12 \\
\hline PF3 & Passo Fundo & URS20 & $40,45,46,38,39,51,58,59,54,56,64,36,55,63,14,35,57,60$ e 61 & 19 \\
\hline PF4 & Passo Fundo & URS21 & $40,45,46,51,58,59,56,64,36,53,14,35,57,60$ e 61 & 15 \\
\hline PF5 & Passo Fundo & URS 21 & $40,45,46,51,58,59,56,36,53,14,35,57,60$ e 61 & 14 \\
\hline PF6 & Passo Fundo & FAPA5 & $40,45,46,38,39,48,51,58,54,64,36,55,63,14,35,57,60$ e 61 & 18 \\
\hline PF7 & Passo Fundo & FAPA5 & $40,45,46,38,39,51,58,59,54,56,62,64,55,63,14,35$ e 61 & 17 \\
\hline PF8 & Passo Fundo & Albasul & $40,45,46,48,51,58,59,56,64,36,53,55,14,35,57,60$ e 61 & 17 \\
\hline PF9 & Passo Fundo & Albasul & $40,45,46,51,58,59,56,64,36,53,14,35,57,60$ e 61 & 15 \\
\hline PF10 & Passo Fundo & Albasul & $40,45,46,51,58,59,56,64,36,53,14,35,57,60$ e 61 & 15 \\
\hline PF11 & Passo Fundo & UFRGS15 & $40,45,46,39,58,59,54,64,53,55,63,35,57,60$ e 61 & 15 \\
\hline PF12 & Passo Fundo & UFRGS15 & $40,45,46,48,51,58,59,56,64,53,14,35$ e 57 & 13 \\
\hline PF13 & Passo Fundo & UFRGS15 & $40,45,46,51,58,59,54,64,36,53,55,14,35,57$ e 61 & 15 \\
\hline Média & & & & 17 \\
\hline
\end{tabular}


foi estimada por meio do índice de coincidência simples (ICS), conforme a equação: ICS = C/N, em que $C$ é o número de genes $P c$ que apresentaram o mesmo padrão de virulência ou avirulência, dentre os $P c$ utilizados, e $\mathrm{N}$ é o número total de genes $P c$ avaliados. Com base na matriz de similaridade gerada, foi construído um dendrograma, pelo método de agrupamento da distância média (UPGMA). Para a verificação do ajuste entre a matriz de similaridade e o dendrograma obtido, foi calculado o coeficiente de correlação cofenética (r), segundo Sokal \& Rohlf (1962). Tais estimativas foram efetuadas com o auxílio do pro- grama computacional NTSYS-pc versão 2.1 (Rohlf, 2000).

Para a avaliação do grau de complementação, entre cada um dos pares de genótipos, em relação à resistência aos isolados, foi proposta a estimativa de um índice denominado de índice de complementação de cultivares (ICC), conforme a equação: $\mathrm{ICC}=(\mathrm{BB}+\mathrm{BA}) / \mathrm{N}$, em que: $\mathrm{BB}$ é o número de isolados a que ambos os genótipos foram resistentes (baixo tipo de infecção); BA é o número de isolados a que um genótipo foi resistente (baixo tipo de infecção) e o outro suscetível (alto tipo de infecção); e N é o número total de isolados. Te-

Tabela 2. Padrão de virulência (alto tipo de infecção - A) e avirulência (baixo tipo de infecção - B), de 40 isolados de Puccinia coronata f. sp. avenae, inoculados em 20 genótipos de aveia ${ }^{(1)}$.

\begin{tabular}{|c|c|c|c|c|c|c|c|c|c|c|c|c|c|c|c|c|c|c|c|c|c|}
\hline \multirow[t]{3}{*}{ Isolado } & \multirow[b]{2}{*}{ UPF } & \multirow[b]{2}{*}{ UPF } & \multirow[b]{2}{*}{ UPF } & \multirow[b]{2}{*}{ UPF } & \multirow[b]{2}{*}{ UPFA } & \multirow[b]{2}{*}{ UPFA } & \multirow[b]{2}{*}{ UFRGS } & \multirow[b]{2}{*}{ UFRGS } & \multicolumn{5}{|c|}{ Genótipo } & \multirow[b]{2}{*}{ FAPA } & \multirow[b]{2}{*}{ FAPA } & \multirow[b]{2}{*}{ FAPA } & \multirow{3}{*}{$\begin{array}{c}\text { Alba- } \\
\text { sul }\end{array}$} & \multirow{3}{*}{$\begin{array}{c}\text { CFT } \\
1 \\
\end{array}$} & \multirow{3}{*}{$\begin{array}{c}\text { CFT } \\
2\end{array}$} & & Total A \\
\hline & & & & & & & & & UFRGS & UFRGS & URS & URS & URS & & & & & & & & \\
\hline & 15 & 16 & 18 & 19 & 20 & 22 & 14 & 15 & 17 & 19 & 20 & 21 & 22 & 4 & 5 & 6 & & & & 15 & \\
\hline$\overline{\mathrm{PF} 1}$ & $\mathrm{~A}$ & $\mathrm{~A}$ & $\mathrm{~A}$ & $\mathrm{~A}$ & $\mathrm{~B}$ & $\mathrm{~A}$ & $\mathrm{~A}$ & $\mathrm{~A}$ & $\mathrm{~A}$ & $\mathrm{~A}$ & B & $\mathrm{A}$ & B & B & $\mathrm{A}$ & $\mathrm{A}$ & B & B & B & $\mathrm{A}$ & 13 \\
\hline PF3 & $\mathrm{A}$ & A & $\mathrm{A}$ & $\mathrm{A}$ & B & A & B & $\mathrm{A}$ & B & A & B & B & $\mathrm{A}$ & B & B & B & A & B & B & A & 10 \\
\hline $\mathrm{PF} 4$ & A & A & $\mathrm{A}$ & A & B & B & A & $\mathrm{A}$ & A & A & B & B & A & A & B & B & A & B & A & A & 13 \\
\hline PF5 & A & A & $\mathrm{A}$ & A & B & B & $\mathrm{A}$ & $\mathrm{A}$ & A & A & B & B & $\mathrm{A}$ & B & A & B & $\mathrm{A}$ & B & B & $\mathrm{A}$ & 12 \\
\hline PF6 & A & $\mathrm{A}$ & $\mathrm{A}$ & A & B & A & $\mathrm{B}$ & A & A & A & A & A & $\mathrm{A}$ & B & B & A & A & B & B & A & 14 \\
\hline PF8 & A & B & $\mathrm{A}$ & A & B & B & $\mathrm{A}$ & $\mathrm{A}$ & A & B & B & A & B & A & B & B & A & B & B & B & 9 \\
\hline PF9 & A & A & A & A & B & A & B & A & A & A & B & A & A & A & B & B & A & A & A & A & 15 \\
\hline PF10 & A & A & $\mathrm{A}$ & A & B & A & B & A & B & A & A & A & A & A & B & B & $\mathrm{A}$ & B & A & A & 14 \\
\hline PF11 & A & A & A & A & B & B & A & A & A & A & B & B & A & A & B & B & A & B & B & A & 12 \\
\hline PF12 & A & A & A & A & B & B & A & A & A & A & B & B & A & A & A & B & A & B & B & A & 13 \\
\hline PF13 & A & A & A & A & B & B & A & A & A & A & B & B & $\mathrm{A}$ & A & B & B & A & B & B & A & 12 \\
\hline PF14 & A & A & A & A & B & A & A & $\mathrm{A}$ & A & B & B & B & B & A & B & B & A & A & A & B & 12 \\
\hline PF15 & A & B & $\mathrm{A}$ & B & B & A & A & A & A & B & B & B & B & A & B & B & A & B & B & B & 8 \\
\hline CL2 & A & A & A & A & B & A & A & A & A & B & B & B & B & A & B & B & B & B & B & B & 9 \\
\hline CL3 & A & $\mathrm{A}$ & $\mathrm{A}$ & A & A & A & B & A & B & A & B & A & A & A & B & B & A & B & B & A & 13 \\
\hline CL4 & A & B & A & A & $\mathrm{A}$ & A & $\mathrm{A}$ & A & A & B & A & B & A & A & A & B & B & A & A & B & 14 \\
\hline CL5 & A & A & B & B & A & B & A & $\mathrm{A}$ & A & B & B & B & B & B & A & A & B & A & A & B & 10 \\
\hline CL6 & A & A & A & A & B & A & A & A & A & B & B & B & B & A & B & B & B & B & A & B & 10 \\
\hline CL7 & A & A & $\mathrm{A}$ & A & A & A & A & A & A & B & A & B & B & A & A & A & B & A & A & B & 15 \\
\hline CL8 & A & A & A & B & B & B & A & A & A & B & A & A & B & A & B & A & B & A & A & B & 12 \\
\hline CL9 & A & A & B & B & $\mathrm{A}$ & B & $\mathrm{A}$ & $\mathrm{A}$ & A & B & A & B & B & A & B & A & B & A & A & B & 11 \\
\hline CL10 & A & A & A & A & B & A & A & A & A & A & B & A & A & B & B & B & A & B & B & A & 13 \\
\hline CL11 & B & A & A & A & A & B & B & B & B & A & B & A & B & A & B & B & A & B & B & B & 8 \\
\hline CL12 & B & A & B & A & B & B & B & B & A & B & B & $\mathrm{A}$ & B & B & B & B & A & B & B & B & 5 \\
\hline PF1 & A & A & A & A & B & A & B & A & B & A & B & B & A & B & B & B & A & B & B & A & 10 \\
\hline PF2 & A & B & A & A & A & A & $\mathrm{A}$ & A & A & B & B & B & B & B & B & B & B & B & B & B & 8 \\
\hline PF3 & A & B & A & B & B & B & A & A & A & B & A & B & B & B & A & A & B & A & A & B & 10 \\
\hline PF4 & A & A & A & A & A & B & B & A & B & A & B & $\mathrm{A}$ & A & B & A & B & A & B & B & $\mathrm{A}$ & 12 \\
\hline PF5 & A & A & A & A & B & A & $\mathrm{B}$ & A & B & A & B & $\mathrm{A}$ & A & B & B & B & A & B & A & A & 12 \\
\hline PF6 & A & B & A & A & A & B & $\mathrm{A}$ & A & A & B & B & $\mathrm{B}$ & B & B & A & B & B & A & A & B & 10 \\
\hline PF9 & A & $\mathrm{A}$ & A & A & B & A & B & $\mathrm{A}$ & B & $\mathrm{A}$ & B & B & $\mathrm{A}$ & B & B & B & A & B & B & $\mathrm{A}$ & 10 \\
\hline PF10 & A & A & A & A & B & A & $\mathrm{B}$ & $\mathrm{A}$ & B & A & B & B & A & B & B & B & A & B & B & A & 10 \\
\hline PF11 & A & B & $\mathrm{A}$ & B & B & A & $\mathrm{A}$ & $\mathrm{A}$ & A & B & B & B & B & A & B & B & B & B & B & B & 7 \\
\hline PF12 & A & $\mathrm{A}$ & $\mathrm{A}$ & A & B & A & $\mathrm{B}$ & $\mathrm{A}$ & B & A & B & B & A & B & B & B & A & B & B & A & 10 \\
\hline PF13 & $\mathrm{B}$ & $\mathrm{A}$ & $\mathrm{B}$ & $\mathrm{A}$ & $\mathrm{B}$ & $\mathrm{B}$ & $\mathrm{B}$ & $\mathrm{A}$ & $\mathrm{B}$ & $\mathrm{A}$ & $\mathrm{B}$ & $\mathrm{B}$ & $\mathrm{A}$ & $\mathrm{B}$ & $\mathrm{A}$ & $\mathrm{B}$ & $\mathrm{B}$ & $\mathrm{B}$ & $\mathrm{A}$ & $\mathrm{A}$ & 8 \\
\hline Total B & 37 & 32 & 36 & 33 & 10 & 25 & 22 & 38 & 25 & 24 & 8 & 14 & 23 & 20 & 11 & 7 & 26 & 10 & 16 & 23 & 440 \\
\hline
\end{tabular}

${ }^{(1)}$ Total A: número de genótipos a que cada isolado apresentou alto tipo de infecção (virulência); Total B: número de isolados que evidenciaram alto tipo de infecção (virulência) em cada genótipo. 
oricamente, quanto mais próximo de um 1 for o valor calculado para o ICC, maior a complementação entre as cultivares, e maior a possibilidade da obtenção de um segregante com ampla resistência aos isolados estudados.

\section{Resultados e Discussão}

A aspersão dos 40 isolados, sobre os 20 genótipos utilizados neste trabalho, resultou em um total de 800 infecções pelo fungo, das quais 441 (55\%) revelaram reação de virulência (alto tipo de infecção) e 359 (45\%) reação de avirulência (baixo tipo de infecção), evidenciando virulência mediana dos isolados estudados sobre os genótipos em questão (Tabela 2); em média, cada isolado apresentou virulência a 11 genótipos. Esta virulência mediana ocorreu, provavelmente, pelo fato de grande parte dos genótipos empregados no estudo serem recentemente recomendados para o uso em escala comercial no Brasil e, desta forma, ainda evidenciam elevada resistência ao fungo (FAPA6, URS20, CFT1, UPFA20, FAPA5 e URS21; Tabela 2). O isolados PF9 e CL7 foram os mais virulentos, pois apresentaram virulência a 15 genótipos cada um; o isolado menos virulento foi o CL12, que apresentou virulência somente a cinco genótipos.

Os isolados empregados neste trabalho revelaram 34 padrões distintos de virulência/avirulência aos genótipos estudados (Figura 1); seis isolados (EL3, PF1, PF8, PF9, PF10 e PF12) revelaram o mesmo padrão de virulência/avirulência, assim como os isolados EL11 e EL13; somente os isolados PF1, PF9 e PF10 apresentaram o mesmo padrão de virulência/avirulência, tanto para os 20 genótipos estudados (Figura 1) quanto para os 25 Pc previamente empregados (Tabela 1). A partir da observação desses fatos, surge a hipótese da existência de grande variabilidade para virulência entre os isolados sul-brasileiros do fungo, uma vez que cada isolado apre-

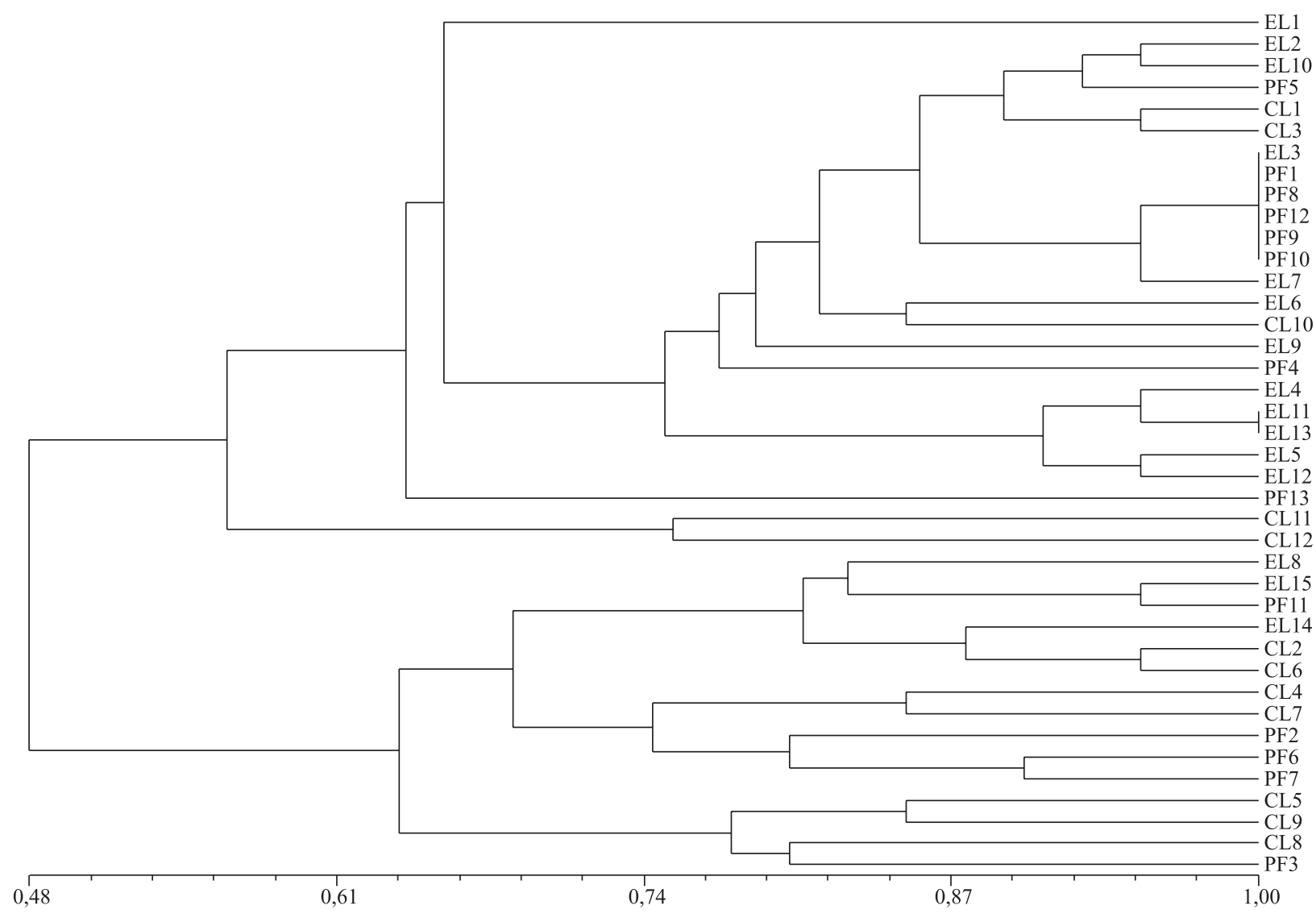

Figura 1. Dendrograma obtido por meio do método de agrupamento UPGMA (distância média), a partir do coeficiente de similaridade de índice de coincidência simples, com base no padrão de virulência e avirulência dos 40 isolados aos 20 genótipos de aveia empregados no estudo. O valor do coeficiente de correlação cofenética (r) foi de 0,85. 
sentou praticamente um padrão diferenciado de virulência/avirulência. Este resultado é contrastante com os descritos por Niekerk et al. (2001), na África do Sul, que, ao avaliar isolados coletados em oito locais, em dois anos, relataram a ocorrência de apenas cinco raças do fungo, das quais apenas uma foi detectada em alta freqüência.

Entre as causas apontadas para a existência de elevada variabilidade, nas populações do fungo causador da ferrugem-da-folha, as mais aceitas são: a recombinação de genes de virulência, via recombinação sexual; a recombinação assexual, por anastomose (via fusão de hifas); e o acúmulo de mutações (Chong \& Seaman, 1994a).

No Brasil, não existem relatos da ocorrência do ciclo sexual do fungo, o que faz com que as principais razões da elevada variabilidade sejam atribuídas à ocorrência de recombinação assexual e ao acúmulo de mutações. Tais mecanismos evolutivos são provavelmente potencializados no Brasil, pelo fato de o patógeno ser amplamente difundido pelo vento (elevada capacidade de dispersão) (Brown \& Hovmoller, 2002). Além disso, como a aveia é cultivada durante o ano todo nos países do Cone Sul, é esperado que a recombinação assexual e o surgimento de mutações ocorram com maior freqüência e se difundam nessa região. O patógeno fica, assim, exposto à ocorrência de mutações e de recombinação assexual durante o ano todo e não somente durante o ciclo da cultura, o que pode ser uma explicação para este cenário. Outra possível explicação é o fato de os isolados terem sido coletados no EBCRA, onde existe uma grande concentração de genótipos elite, que apresentam, no conjunto, um grande número de genes de resistência. Isto gera uma forte pressão de seleção sobre os patógenos, fazendo com que somente consigam se estabelecer os isolados que contenham um número elevado de genes de virulência.

Observando-se a Figura 1, e utilizando-se como critério arbitrário para divisão de grupos a similaridade de 0,60, é possível dividir os 40 isolados em três grupos (de acordo com o padrão de virulência/avirulência), em que o grupo I é constituído pelos isolados PF2, PF3, PF6, PF7, PF11, CL2, CL4, CL5, CL6, CL7, CL8, CL9, EL8, EL14 e EL15; o grupo II, pelos isolados CL11 e CL12; e o grupo III, pelos demais isolados. Foi verificada a inexistência de um padrão claro de distribuição da variabilidade para a virulência dos isolados, uma vez que não foi detectada uma tendência forte de agrupamento dos isolados por local de origem; isto significa que a variabilidade da virulência está igualmente distribuída nos três locais de coleta. Tal cenário pode ter por base duas explicações: os isolados apresentam alta mobilidade, por meio do vento, e por isso estão presentes, quase que uniformemente, nos diferentes locais; os isolados foram coletados sobre o EBCRA, que é representado pelos mesmos genótipos nos três locais, o que levou à ausência de estratificação dos isolados de acordo com sua origem.

Verificou-se elevada variabilidade genética entre os genótipos, no que diz respeito à resistência/suscetibilidade à ferrugem-da-folha da aveia, uma vez que cada um dos genótipos mostrou um padrão distinto de resistência/suscetibilidade aos isolados (Tabela 2). Além disso, alguns genótipos apresentaram resistência a um elevado número de isolados, enquanto outros apresentaram suscetibilidade a quase todos os isolados estudados. Neste contexto, merecem destaque, em função da elevada resistência, as cultivares FAPA6, URS20, UPFA20, CFT1 e FAPA5, enquanto os genótipos UFRGS15, UPF15, UPF18, UPF19 e UPF16 expressaram suscetibilidade à maioria dos isolados (Tabela 2).

Uma vez que os genótipos apresentaram elevada variabilidade para resistência à ferrugem-da-folha da aveia, é possível que, por meio da hibridação artificial entre estes, seja possível a seleção de genótipos transgressivos para resistência a essa doença. Nesse sentido, foi proposta a adoção do índice de complementação de cultivares (ICC) como critério para a seleção de possíveis genitores (Tabela 3). Tal índice é baseado na premissa de que os genótipos mais promissores para cruzamento artificial são aqueles que, no conjunto, apresentam resistência à maioria dos isolados. Entretanto, além dos genótipos apresentarem elevada complementação quanto à resistência à ferrugem-da-folha, é necessário que os mesmos apresentem elevado potencial agronômico, o que é satisfeito pelo fato de todos os genótipos (exceto a linhagem URPEL15) serem recomendados para o cultivo no Brasil.

Merecem destaque, como possíveis genitores para a formação de populações segregantes, as combinações entre os genótipos FAPA6 x Albasul, URS22 x FAPA6, CFT1 x UFRGS19 e CFT1 x URPEL15, que evidenciaram ICC de 0,98 (Tabela 3). Isto significa que, por meio da combinação entre estes genótipos, é possível a seleção de segregantes resistentes a 39 dos 40 isolados avaliados. Além disso, também podem ser indicadas como 
Tabela 3. Matriz dos índices de complementação de cultivares (ICC), estimada por meio do padrão de resistência/suscetibilidade de 20 genótipos de aveia a 40 isolados de Puccinia coronata f. sp. avenae.

\begin{tabular}{|c|c|c|c|c|c|c|c|c|c|c|c|c|c|c|c|c|c|c|c|}
\hline Genótipo & $\begin{array}{c}\text { UPF } \\
15 \\
\end{array}$ & $\begin{array}{c}\text { UPF } \\
16 \\
\end{array}$ & $\begin{array}{c}\text { UPF } \\
18 \\
\end{array}$ & $\begin{array}{c}\text { UPF } \\
19 \\
\end{array}$ & $\begin{array}{c}\text { UPFA } \\
20 \\
\end{array}$ & $\begin{array}{c}\text { UPFA } \\
22 \\
\end{array}$ & $\begin{array}{c}\text { UFRGS } \\
14 \\
\end{array}$ & $\begin{array}{c}\text { UFRGS } \\
15 \\
\end{array}$ & $\begin{array}{c}\text { UFRGS } \\
17 \\
\end{array}$ & $\begin{array}{c}\text { UFRGS } \\
19 \\
\end{array}$ & $\begin{array}{c}\text { URS } \\
20 \\
\end{array}$ & $\begin{array}{c}\text { URS } \\
21 \\
\end{array}$ & $\begin{array}{c}\text { URS } \\
22 \\
\end{array}$ & $\begin{array}{c}\text { FAPA } \\
4 \\
\end{array}$ & $\begin{array}{c}\text { FAPA } \\
5 \\
\end{array}$ & $\begin{array}{c}\text { FAPA } \\
6 \\
\end{array}$ & Albasul & $\begin{array}{c}\text { CFT } \\
1 \\
\end{array}$ & $\begin{array}{c}\text { CFT } \\
2 \\
\end{array}$ \\
\hline UPF16 & 0,28 & & & & & & & & & & & & & & & & & & \\
\hline UPF18 & 0,13 & 0,30 & & & & & & & & & & & & & & & & & \\
\hline UPF19 & 0,25 & 0,28 & 0,23 & & & & & & & & & & & & & & & & \\
\hline UPFA20 & 0,78 & 0,85 & 0,80 & 0,83 & & & & & & & & & & & & & & & \\
\hline UPFA22 & 0,38 & 0,50 & 0,38 & 0,45 & 0,88 & & & & & & & & & & & & & & \\
\hline UFRGS14 & 0,45 & 0,65 & 0,50 & 0,63 & 0,83 & 0,73 & & & & & & & & & & & & & \\
\hline UFRGS15 & 0,08 & 0,25 & 0,13 & 0,23 & 0,78 & 0,38 & 0,45 & & & & & & & & & & & & \\
\hline UFRGS17 & 0,40 & 0,58 & 0,45 & 0,55 & 0,83 & 0,68 & 0,45 & 0,40 & & & & & & & & & & & \\
\hline UFRGS19 & 0,45 & 0,40 & 0,43 & 0,40 & 0,93 & 0,60 & 0,83 & 0,43 & 0,78 & & & & & & & & & & \\
\hline URS20 & 0,80 & 0,85 & 0,83 & 0,88 & 0,93 & 0,88 & 0,88 & 0,80 & 0,85 & 0,93 & & & & & & & & & \\
\hline URS21 & 0,70 & 0,68 & 0,68 & 0,68 & 0,93 & 0,78 & 0,90 & 0,70 & 0,83 & 0,73 & 0,93 & & & & & & & & \\
\hline URS22 & 0,45 & 0,45 & 0,45 & 0,43 & 0,93 & 0,60 & 0,83 & 0,43 & 0,78 & 0,45 & 0,90 & 0,78 & & & & & & & \\
\hline FAPA4 & 0,53 & 0,60 & 0,53 & 0,60 & 0,88 & 0,70 & 0,65 & 0,53 & 0,63 & 0,75 & 0,88 & 0,80 & 0,75 & & & & & & \\
\hline FAPA5 & 0,75 & 0,83 & 0,78 & 0,80 & 0,85 & 0,90 & 0,78 & 0,73 & 0,78 & 0,88 & 0,93 & 0,95 & 0,88 & 0,93 & & & & & \\
\hline FAPA6 & 0,83 & 0,85 & 0,88 & 0,93 & 0,93 & 0,93 & 0,85 & 0,83 & 0,83 & 0,95 & 0,88 & 0,93 & 0,98 & 0,93 & 0,90 & & & & \\
\hline Albasul & 0,40 & 0,40 & 0,38 & 0,38 & 0,93 & 0,58 & 0,78 & 0,40 & 0,70 & 0,45 & 0,93 & 0,70 & 0,48 & 0,68 & 0,93 & 0,98 & & & \\
\hline CFT1 & 0,75 & 0,85 & 0,80 & 0,88 & 0,85 & 0,88 & 0,78 & 0,75 & 0,75 & 0,98 & 0,88 & 0,95 & 0,95 & 0,85 & 0,85 & 0,88 & 0,95 & & \\
\hline CFT2 & 0,63 & 0,70 & 0,68 & 0,73 & 0,85 & 0,78 & 0,73 & 0,60 & 0,70 & 0,85 & 0,85 & 0,88 & 0,83 & 0,75 & 0,83 & 0,88 & 0,85 & 0,75 & \\
\hline URPEL15 & 0,45 & 0,43 & 0,45 & 0,43 & 0,95 & 0,60 & 0,83 & 0,43 & 0,78 & 0,43 & 0,93 & 0,75 & 0,45 & 0,78 & 0,88 & 0,95 & 0,48 & 0,98 & 0,85 \\
\hline
\end{tabular}

promissoras as combinações entre os genótipos URPEL15 x UPFA20, UFRGS19 x FAPA6, URS21 x FAPA5, URS21 x CFT1, URS22 x CFT1, FAPA6 $x$ URPEL15 e Albasul x CFT1, que evidenciaram ICC de 0,95 (Tabela 3), podendo-se, teoricamente, permitir a seleção de genótipos resistentes a 38 dos 40 isolados estudados. As combinações menos promissoras quanto à resistência à ferrugem-da-folha foram: UFRGS15 x UPF15, UPF18 x UPF15 e UFRGS15 x UPF18, que demonstraram ICC de 0,08, 0,13 e 0,13, respectivamente (Tabela 3). Porém, cabe ressaltar que o ICC não leva em consideração a herdabilidade da resistência, nem a interação ou a ligação entre os possíveis genes de resistência presentes nos genótipos, o que pode dificultar o processo de seleção. Além disso, nenhuma das combinações de cultivares possibilita a seleção de genótipos resistentes a todos os isolados estudados. Em função deste cenário de grande dificuldade de controle da moléstia, por meio da resistência qualitativa (determinada por um ou poucos genes), ganha força a possibilidade da adoção de novas estratégias, para que seja alcançada uma resistência durável e efetiva, prevenindo assim a ocorrência de epidemias de ferrugem-da-folha. Neste sentido, vem sendo sugerida a utilização da resistência quantitativa (determinada por genes menores), a qual não impõe uma pressão de seleção tão intensa sobre a população do patógeno, quanto a resistência qualitativa, em relação à virulência (Chaves et al., 2004).

\section{Conclusões}

1. Os genótipos de aveia estudados apresentam resistência mediana à ferrugem-da-folha da aveia.

2. A população de Puccinia coronata f. sp. avenae do Rio Grande do Sul apresenta elevada variabilidade e virulência.

3. As combinações FAPA6 x Albasul, URS22 x FAPA6, CFT1 x UFRGS19 e CFT1 x URPEL15 são possíveis genitores de populações segregantes, entretanto nenhuma delas possibilita a seleção de genótipos resistentes a todos os isolados estudados.

\section{Agradecimentos}

À Fapergs, ao CNPq e à CAPES, pela concessão de auxílio e de bolsas de pós-graduação e produtividade em pesquisa; à Embrapa Trigo de Passo Fundo.

\section{Referências}

BENIN, G.; CARVALHO, F.I.F. de; OLIVEIRA, A.C.; LORENCETTI, C.; VIEIRA, E.A.; COIMBRA, J.L.M.; VALÉRIO, I.P.; FLOSS, E.L.; BERTAN, I.; SILVA, G.O. da. Adaptabilidade e 
estabilidade em aveia em ambientes estratificados. Ciência Rural, v.35, p.295-302, 2005.

BROWN, J.K.M.; HOVMOLLER, M.S. Aerial dispersal of pathogens on the global and continental scales and its impact on plant disease. Science, v.297, p.537-541, 2002.

CAIERÃO, E.; CARVALHO, F.I.F. de; FLOSS, E.L.; SÁNCHEZCHACÓN, C.D.; LORENCETTI, C.; MARCHIORO, V. Efeito de níveis de severidade e incidência da ferrugem-da-folha e ferrugemdo-colmo no rendimento de linhagens de aveia. Pesquisa Agropecuária Brasileira, v.36, p.43-52, 2001.

CHAVES, M.S.; MARTINELLI, J.A.; FEDERIZZI, L.C. Resistência quantitativa à ferrugem-da-folha em genótipos de aveia branca: I - Caracterização da reação em condições de campo. Fitopatologia Brasileira, v.29, p.35-42, 2004.

CHONG, J.; LEONARD, K.J.; SALMERON, J.J. A North American system of nomenclature for Puccinia coronata f. sp. avenae. Plant Disease, v.84, p.580-585, 2000.

CHONG, J.; SEAMAN, W.L. Distribution and virulence of Puccinia coronata f. sp. avenae in Canada in 1992. Canadian Journal of Plant Pathology, v.16, p.64-67, 1994a.

CHONG, J.; SEAMAN, W.L. Incidence and virulence of Puccinia coronata f. sp. avenae in Canada in 1993. Canadian Journal of Plant Pathology, v.16, p.335-340, 1994b.

DOEHLERT, D.C.; McMULLEN, M.S.; HAMMOND, J.J. Genotypic and environmental effects on grain yield and quality of oat grown in North Dakota. Crop Science, v.41, p.1066-1072, 2001.

FALCONER, D.S.; MACKAY, T.F. Introduction to quantitative genetics. $4^{\text {th }}$ ed. New York: Prentice Hall, 1996. 464p.

FLOR, H.H. The complementary genetic systems in flax and flax rust. Advances in Genetics, v.8, p.29-54, 1956.
HOLLAND, J.B.; MUNKVOLD, G.P. Genetic relationships of crow rust resistance, grain yield, test weight, and seed weight in oat. Crop Science, v.41, p.1041-1050, 2001.

LORENCETTI, C.; CARVALHO, F.I.F. de; MARCHIORO, V.S.; BENIN, G.; OLIVEIRA, A.C. de; FLOSS, E.L. Implicações da aplicação de fungicida na adaptabilidade e estabilidade de rendimento de grãos em aveia branca. Ciência Rural, v.34, p.693-700, 2004.

MARTINELLI, J.A.; FEDERIZZI, L.C.; BENNEDETI, A.C. Redução do rendimento de grãos de aveia em função da severidade da ferrugem-da-folha. Summa Phytopathologica, v.20, p.116-118, 1994.

NIEKERK, B.D. van; PRETORIUS, Z.A.; BOSHOFF, W.H.P. Pathogenic variability of Puccinia coronata f. sp. avenae and P. graminis f. sp. avenae on oat in South Africa. Plant Disease, v.85, p.1085-1090, 2001.

ROHLF, F.J. NTSYS-pc: numerical taxonomy and multivariate analysis system, version 2.1. New York: Exeter Software, 2000. 38p.

SIMONS, M.D. Crown rust. In: ROELFS, A.P.; BUSHNELL, W.R. (Ed.). The cereal rusts: diseases, distribution, epidemiology, and control. Orlando: Academic Press, 1985. v.2, p.132-172.

SIMONS, M.D.; MURPHY, H.C. Oat diseases. In: COFFMAN, F.A. (Ed.). Oats and oat improvement. Madison: American Society of Agronomy, 1961. p.330-390.

SOKAL, R.R.; ROHLF, F.J. The comparison of dendrograms by objective methods. Taxon, v.11, p.30-40, 1962.

VIEIRA, E.A. Genética da interação: Puccinia coronata f. sp. avenae $\mathrm{x}$ aveia branca (Avena sativa). 2005. 96p. Tese (Doutorado) - Universidade Federal de Pelotas, Pelotas. 